\title{
MAIO 68, SUBLIME E HORRÍVEL
}

\author{
(Notas pontuais de um europeu contemporâneo) ${ }^{1}$
}

\section{Amadeu Lopes Sabino*}

No 18 de Brumário, Karl Marx formula a conhecida intuição (depois feita lei de bronze do materialismo histórico) segundo a qual a tragédia da História se repete enquanto farsa. Nietzsche dirá mais tarde, nas Considerações extemporâneas, que tudo o que de sublime foi outrora possível será ainda de novo possível no futuro. Heráclito, filósofo da mutabilidade, tinha descoberto o contínuo rio da existência, mas advertido que ninguém se banha duas vezes na mesma água desse rio. Na história da Europa, o ano sublime de1968 é um ano charneira que tem um precedente no ano de 1848 - o da primavera dos povos. Carateriza-os a simultaneidade de movimentos sociais e políticos em todo o continente, o que reforça o sentimento de uma realidade europeia que se sobrepõe às fronteiras que repartem impérios, estados e nações. Em 1848, a realidade europeia era ainda a dos impérios, e as forças nacionais e liberais levantaram-se contra as entidades plurinacionais em nome da liberdade das pátrias e dos indivíduos: contra os impérios dinásticos, contra o império austro-húngaro, contra os estados papais e também (o que prenunciava tempos a haver) contra a monarquia burguesa de Luís Filipe. Em 1968, após a prosperidade de três décadas, les trois glorieuses que se seguem à II Guerra mundial, a geração dos filhos da guerra encontra-se perante algo de novo: uma crise económica. O rio continuava a correr, as águas eram outras. Depois de amanhã não há, escrevera Alberto Caeiro, um dos muitos Fernando Pessoa, poeta que começava a ser descoberto pela Europa a partir do annus mirabilis de 1960, data da aparição da antologia da Seghers. Desapossados de futuros radiosos que a prosperidade prometera, os jovens recusam o autoritarismo dominante na sociedade, na empresa e na universidade. Como é próprio dos movimentos coletivos fundados na desilusão, a juventude (mais concretamente a juventude universitária, uma espécie de intelectual orgânico da juventude) inventa a sua própria utopia. Para o jovem antissalazarista que eu era, habituado à censura prévia administrativa em Portugal, foi com espanto que descobri, nas minhas primeiras idas a França, os vistos da censura no cinema. Era uma censura limitada ao cinema, moderadamente a outros espetáculos, ausente dos livros e da imprensa. Não censurava a crítica política, censurava a imoralidade e a libertinagem. A França de De Gaulle, cenário das jornadas

\footnotetext{
${ }^{1} \mathrm{O}$ texto constitui-se de um conjunto de notas que serviram de base a uma intervenção oral do autor no VI Colóquio do Centro de Estudos Portugueses da UFPR, “Existir, Resistir: Rexistir”, realizado de 23 e 25 de outubro de 2018.

* Amadeu Lopes Sabino, Elvas, 1943. Em Portugal, foi advogado, jornalista (Diário de Lisboa e O Tempo e o Modo) e docente universitário. Preso pela PIDE (Polícia Internacional e de Defesa do Estado) e incorporado no exército em regime disciplinar, exilou-se na Suécia entre 1973 e 1975. Funcionário internacional de 1983 a 2008, foi conselheiro jurídico e diretor no Serviço Jurídico do Conselho da União Europeia, em Bruxelas. Ficcionista e ensaísta, é, de acordo com Eduardo Lourenço (in “Navegadores por ruas estrangeiras”, prefácio a Identidades Fugidias, Guarda, 2001), um dos “autores que, por distantes da pátria, apesar de conhecidos, não gozam ainda daquela reputação que visivelmente merecem”. Escritor da expatriação, da ausência, dos exílios exteriores e interiores, evoca, sempre de acordo com Eduardo Lourenço, a vivência do estrangeiro, "amarga como muitas, mas, como poucas, libertadora”. Romancista e contista marcado pela “agilidade da narração e por um requintado hedonismo” (História da Literatura Portuguesa, 17 ed., de António José Saraiva e Óscar Lopes). Última obra publicada: O todo ou o seu nada, romance, Bizâncio, Lisboa, 2018.
} 
de maio, era pudica e hipócrita, como os filmes de Chabrol amplamente ilustram. O princípio da autoridade presidia ao quotidiano de uma nação em que os filhos, os estudantes, as mulheres e os trabalhadores obedeciam, o patrão e o pai mandavam, e os jovens, alguns jovens, afiavam os punhais de uma vingança cujos contornos ainda ignoravam. Qualquer ser humano foi, um dia, um Édipo em potência na fantasia, e todos recuam, horrorizados, diante da realização do sonho. Os jovens franceses e europeus dos anos 60 eram Édipos em potência. Maio de 68 e o que, no continente, se lhe seguiu representaram a passagem da potência ao ato.

A nostalgia é má conselheira - sobretudo nas histórias e na política -, difunde torrentes de sentimentalismo lacrimejante e conduz àquilo a que Nietzsche (um autor reabilitadíssimo após 68, sobretudo através de Michel Foucault) chama a história monumental - um mito repressivo, que ofusca a realidade possível dos factos através de narrativas heroicas. Cohn-Bendit, o judeu franco-alemão que personalizou e personaliza o maio de 68, costuma dizer: j'ai en marre de 68 , estou farto de 68. Identifico-me com essa recusa perversa em embalsamar os protagonistas de algumas andanças que o destino colocou no nosso percurso: no meu caso, as lutas estudantis, a prisão, o exílio, a luta pela democracia e contra a guerra colonial. Tenho tido ocasião de falar de tudo isto, mas começo cada vez mais a recusar fazê-lo - exceto quando, como hoje, me encontro perante um auditório académico, que se propõe a contribuir para compreender o nosso passado próximo. Tentarei, pois, ser objetivo e não revivalista. Na memória política, a saudade é má companhia, na medida em que tende a confundir distopias com utopias.

Na juventude, quando comecei a interessar-me pela política, sobressaía na oposição a Salazar uma plêiade de velhos militantes da primeira república (1910-1926) que, marginalizados pela ditadura, veneravam o regime republicano enquanto paradigma, descrevendo-o como um éden, que contrapunham à ditadura salazarista - o Estado Novo português (1926-1974). Os republicanos históricos (ou histéricos, como a irreverência da juventude estudantil democrática os designavam) viam no passado da Primeira república o futuro da república democrática a implantar. Enganavam-se em relação ao passado - a primeira república foi uma democracia mais que imperfeita; e enganavam-se também, felizmente, em relação ao futuro que é hoje o nosso presente - a atual república portuguesa parece-se com muitas coisas, portuguesas e europeias, e parece-se muito pouco com a república de 1910. Os náufragos da Primeira república tropeçavam na armadilha da nostalgia, hoje existente em Portugal em relação ao 25 de abril de 74 (data da queda do Estado Novo) e na minha geração de europeu em relação ao maio de 1968. O propósito de transformar um acontecimento em mito é recorrente. Em Mythologies, Roland Barthes, um dos pensadores que marcou 68, define o mito como uma duplicação, uma sobreposição do conjunto significante/significado que cria um novo significado. Através da duplicação, o mito realiza uma crença. O Citroën deixa de ser um mero automóvel para se transformar num ícone da civilização moderna e da vida doméstica. Greta Garbo deixa de ser a atriz de Ninotchka e passa a representar a eterna juventude. A astrologia deixa de ser uma fantasia criativa para se tornar uma profecia. Maio de 68 passou a ser um mito urbano moderno, Cohn-Bendit outro. Tentemos falar de 68 para além da crença. 
Entre os eventos que antecedem e prenunciam o maio francês sobressai o movimento contra a guerra do Vietname, que era europeu, americano, ocidental, mobilizando, a partir da segunda metade dos anos 60, jovens universitários e forças políticas em toda a Europa. É na sequência das manifestações de fevereiro de 1967 contra a intervenção americana no Sudoeste asiático, e em defesa das forças anti-imperialistas locais, que surge, na cidade universitária de Nanterre, em Paris, o movimento de 22 de março que, protestando contra a proibição de entrada de estudantes nos dormitórios do sexo oposto, se transforma rapidamente na recusa do autoritarismo na sociedade e, mais concretamente, na escola. O gaullismo (1958-1969) foi um regime paradoxal, democrático e autoritário, fundado à medida do general que representou a honra de França durante a ocupação. De Gaulle, como outros depois dele, retoma a imagem e a herança de Napoleão. É Napoleão IV, num país que é ainda uma França tradicional e em grande medida rural. O princípio da autoridade prevalece: na família, na empresa, na escola. Como depois recordará Raymond Aron, um intelectual de direita que escreveu um livro essencial sobre maio de 68 - La Révolution introuvable - não havia em França $a$ Universidade com maiúscula, o ensino superior encontrava-se totalmente dependente do Ministério da Educação Nacional e sem qualquer autonomia; o reitor, o senado, os professores, os programas, os cursos, tudo respondia perante o ministro. A fúria dos estudantes de Nanterre tem por alvo as instituições académicas e sociais, mais do que as instituições políticas. Ora, eram as instituições da sociedade civil que fundavam o paradoxo do regime, democrático no topo político e autoritário na base social. Cabe, a propósito, mencionar Michel Foucault, cuja obra se centra, a partir de 1966, na crítica das instituições sociais repressivas: as psiquiátricas, o sistema carcerário, o sistema hospitalar e o sistema educativo. Foucault tinha como modelo não só a França do general de Gaulle, mas também a Europa desses anos, não apenas a das ditaduras ocidentais - Espanha e Portugal, depois Grécia - e orientais, os países submetidos a Moscovo, mas a Europa como um todo. Nos anos 60, a Europa é ainda patriarcal, masculina, tradicionalista, conservadora na direita e na esquerda, esta com frequência moralmente mais conservadora do que a direita.

Como ponto de partida, os ativistas do movimento estudantil francês têm um programa bem simples nos propósitos e bem complexo nos resultados de recusa de uma França e de uma Europa impavidamente submissas ao patriarcado. Mais do que um programa, trata-se de um caderno de atribuições, pois que, na segunda metade dos anos 60 , a juventude pratica já, sem remorso nem hipocrisia, uma liberdade afirmada das consciências e dos corpos. Os acontecimentos da primavera de 1968 vão conferir uma narrativa épica a essas práticas. Entre 3 e 13 de maio, a revolta estudantil sai do campus de Nanterre e ocupa as ruas de Paris, defrontando as forças da ordem em barricadas de calçadas destruídas, árvores arrancadas, pedras lançadas contra edifícios públicos. O incêndio da Bolsa e a ocupação das escolas (acima de tudo a ocupação da Sorbonne) simbolizam a tomada de Paris pelos novos enragés. Em 13 de maio, uma outra sucessão de eventos reforça e, ao mesmo tempo, desvia o rumo da revolta de maio. A CGT (organização sindical comunista) decreta uma greve geral. Em 20 de maio, 10 milhões de franceses estão em greve. O Partido Comunista exibe uma força oposta à dos movimentos 
esquerdistas que qualifica de aventureiros e anarquistas (adjetivos pejorativos para as esquerdas oficiais) e avança com reivindicações políticas, ou antes, estritamente políticas e económicas: um novo governo, eleições, aumentos de salários, contratação coletiva. Mendès France e François Mitterrand, dois socialistas, afirmam-se prontos para ocupar o poder. De Gaulle desaparece durante algumas horas, refugiado em Baden-Baden no quartel-general das forças francesas na Alemanha ainda ocupada. Demite-se? Não, regressa com um fôlego que simula o de outrora. Pompidou, o primeiro-ministro, também ele gaullista, assume o controlo do estado. Aceita a mão estendida dos sindicatos, com quem o governo, indo ao encontro das reivindicações sindicais, celebra os acordos de Grenelle. De Gaulle dissolve o Parlamento, e nas eleições de 23 e 30 de junho, a França profunda, aterrorizada com a desordem e a violência nas ruas, confere a maioria absoluta aos partidos de direita. As jornadas de maio-junho oscilam entre o sublime e o horrível. A ordem pública é restabelecida, os grupos maoístas e anarquistas são cirurgicamente dissolvidos. O país regressa aos eixos, mas a sociedade não é a mesma a partir de maio: uma onda de liberdade social, de costumes e de irreverência atravessava a França e a Europa. A palavra libertou-se e os slogans de 68 ilustram os novos tempos: Il est interdit d'interdire, Jouissez sans entraves, Eléctions, piège à cons, Je suis marxiste, tendance Groucho, Marx, Mao, Marcuse!, Cela nous concernes tous, Soyez réalistes, demandez d'impossible, Sous les pavés, la plage! ${ }^{2}$ A partir desses tempos-charneira, a autoridade e a proibição são tidas por ilegítimas. A nossa pós-modernidade presente continua marcada por esse anátema.

Como resumir o que, de essencial, carateriza o terramoto que, em convenção calendarizada, designamos por maio de 68 ? Há uma raiz anti-imperialista, antiamericana, nos confrontos de rua que o precedem. É nesse quadro que se inserem as ações contra a constrição militar. Nos EUA, os soldados que lutavam e morriam no Vietname cumpriam serviço militar obrigatório. De igual modo em França, durante a guerra da Argélia. Contra a tropa e contra as autoridades estabelecidas, maio de 68 define-se pelo antiautoritarismo. Nos anos 60, as sociedades europeias são atravessadas por movimentos pela igualdade dos sexos, feministas, ecologistas, LGBT, pela legalização do aborto, pela contestação civilizacional, por práticas familiares e sociais alternativas. Todo esse amálgama é simultaneamente causa e efeito do sucesso de 68. Do ponto de vista político, o que de essencial e salutar ficou foi o início da irreversível decadência do domínio dos comunistas pró Moscovo e da União Soviética nas esquerdas europeias. Guy Mollet, um socialista, podia então afirmar com propriedade e eco que os comunistas não estavam à esquerda, mas a leste. A queda das casas comunistas marca o termo do marxismo na versão estalinista, ditatorial, na teoria das esquerdas europeias. Mesmo os marxismos de Henri Lefebvre, de Louis Althusser, de Nikos Poulantzas ou de Lucien Sebag nada têm a ver com o da Academia das Ciências da União Soviética ou do Instituto Max-Engels-Lenine. A extrema da esquerda rompia com o comunismo pró-soviético e aderia ao maoísmo. Intelectuais e ativistas viam na União Soviética o que a União Soviética era - uma ditadura sobre o povo -, e não viam na China Popular o que a China Popular já era. O que a China hoje é, pública e notoriamente, estava contido no que a China e o maoísmo chinês eram nos anos 60 e 70 do

${ }^{2}$ É proibido proibir, Goze sem entraves, Eleições, armadilha para estúpidos, Sou marxista de linha Groucho, Marx, Mao, Marcuse! Isso diz respeito a todos nós, Sejam realistas, peçam o impossível, Sob as pedras do calçamento, a praia! 
século passado. Para os que nele encontraram uma religião pagã libertadora, o maoísmo foi, ex aequo com o comunismo soviético e os fascismos, uma das alucinações funestas do século XX. No entanto, o maoísmo europeu idealizava no Império do Meio a utopia da liberdade, da igualdade e da fraternidade - proletárias, populares, universais.

Que foi maio de 68: uma revolução, uma revolta, um incidente, um acidente? A partir do termo criado para designar os revoltosos de 1848, les quarante-huitards, que agitaram a Europa, de Berlim a Varsóvia, da Dinamarca à Itália, de Paris a Lisboa, crismaram-se de soixante-huitards os que, depois do levantamento parisiense de 1968, ocupavam escolas, ruas e fábricas do continente - que de velho, se tornava novo. Entre outras, as manifestações na Alemanha Federal contra a guerra no Vietname, contra as medidas de exceção e de repúdio do atentado que vitimou o dirigente estudantil Rudi Dutschke, as greves e lutas estudantis do maggio rampante italiano, o movimento belga de 13 de maio, a primavera de Praga, e j'en passe, ecoam os acontecimentos franceses por todo o continente. Era, como 120 anos antes, uma primavera das nações? As aparências e as evidências são sempre enganadoras. Tratava-se de algo diferente, provavelmente novo. As nações e o estados-nações já não moviam a história europeia. Era, na Europa e na América do Norte, o sinal da crise da prosperidade que, durante três décadas, sucedera à Segunda Guerra Mundial. Era o fim da perda do papel central do hemisfério Norte no governo do mundo, assinalado pelas descolonizações, pelos conflitos coloniais, pela Guerra do Vietname. Proudhon, pensador socialista do século XIX, dizia, referindo-se à revolução de 1848 em França: “Fez-se uma revolução sem uma ideia. A França é uma nação de comediantes.” Meio século antes, o duque de La Rochefoucauld-Liancourt, chefe do guarda-roupa real, despertava Luís XVI para lhe anunciar a tomada da Bastilha. "É uma revolta?”, perguntou o rei. “Não, Sire, é uma revolução.” Talvez em 68 se pensasse o contrário - o contrário de 1789 e o contrário de 1848. Havia ideias, mas havia ideias de mais. Não era uma revolução na medida em que não tinha como objetivo a mudança do poder, político, mas era mais do que uma revolta, ou antes, de uma sucessão de revoltas - contra as instituições herdadas do apogeu do estado nacional, mais do que contra o poder político. Em 1917, a revolução russa conquistou o Palácio de Inverno, o símbolo do poder. O mesmo tinha feito a revolução francesa em 1789 com a tomada da Bastilha. Em Paris, em 68, os revoltosos dinamitam o universo descoberto por Freud e pela Escola de Frankfurt, subvertendo as consciências de modo a ilegitimar as instituições sociais autoritárias - a família, a escola, a fábrica, o trabalho, até a igreja, para os que eram crentes. Nesse leque amplo e profundo de consequências, 68 foi mais do que uma revolução. Eric Hobsbawm considera que o século XX começou em 1918 com o fim da Primeira guerra mundial e terminou em 1989-90 com o desmoronamento da URSS e dos países ditos socialistas. 1968 partiu o século ao meio. Na esteira de Nietzsche, descobre-se que quando a autoridade se torna ilegítima tudo é permitido e nada é proibido. Raymond Aron define então os acontecimentos de 68 como uma revolution introuvable. Não era possível encontrá-la porque estava em todo o lado. A partir desses anos intelectualmente tumultuosos, Nietzsche, Lacan, Debord, Marcuse e Foucault permitem, mais do que as cartilhas marxistas, uma leitura do real da modernidade ou, como rapidamente se dirá, da pós-modernidade. Com o ano sublime e horrível de 1968 iniciamos a entada no puzzle de situações sem solução e das 
respostas sem perguntas que é a marca dos tempos presentes. Um dos pensadores que melhor define a época que 68 prenuncia, a do capitalismo desenvolvido e da resistência do individuo a um totalitarismo que se ignora, é Herbert Marcuse, um dos herdeiros da Escola de Frankfurt e do método da teoria crítica. Marcuse assinala o caráter repressivo do princípio da realidade. A tentação da liberdade, considera, não condiciona os desejos em nome da realidade, realiza-os. O filósofo, alemão de origem e americano de naturalização, cujos escritos inspiraram os movimentos estudantis da Califórnia, critica a tolerância repressiva, aceitação das diferenças desde que estas não toquem nas estruturas do poder, o que na sociedade capitalista avançada representa "uma repressão democrática da liberdade.”

\section{E Portugal?}

A minha geração (a última geração francófona e francófila da Europa, antes da vitória linguística e cultural anglo-americana) educou-se na literatura francesa e na leitura em francês dos clássicos do marxismo - às vezes também nas edições em português da Zahar e, em espanhol, do Fondo de Cultura Económica, que, iludindo as censuras, chegavam irregularmente a Portugal e a Espanha. Nascido e criado na raia de Espanha, desde cedo adicionei aos meus saberes as leituras em espanhol e os livros adquiridos na vizinha Badajoz. A partir dos anos 60, esclareça-se, a liberdade de circulação de livros e filmes, se não de ideias, era superior na Espanha de Franco à do Portugal de Salazar. Para a minha geração, a do 68 português e do abril de 74, a França era uma pátria mental. Tínhamos duas pátrias, Portugal e França, como os espanhóis tinham a sua própria e a França, os italianos do mesmo modo, e os gregos, os alemães, os belgas, os holandeses... Líamos em francês, citávamos autores franceses, interpretávamos a política nacional pela similitude, muitas vezes forçada, com a França, cantávamos o chant des partisans -, e os nossos sonhos sentimentais e eróticos eram sobretudo franceses. Digo-o, uma vez mais, sem nostalgia. Portugal era demasiado pobre para um maio de 68 idêntico ao francês. Era uma ditadura enredada numa sucessão de guerras coloniais nos confins de um império que parecia eterno. Qualquer manifestação de rua era ilegal e reprimida. Pensar era perigoso, exprimir o pensamento uma questão para a censura e para a polícia. A contestação era, por isso mesmo, sobretudo política, mais do que de costumes e civilizacional. No entanto, não foi preciso esperar por nenhum movimento de rua para que a liberdade de costumes abalasse a sociedade portuguesa. Já em pleno Estado Novo, largos setores dos meios urbanos viviam desprezando preconceitos e lugares seletos de uma sociedade governada por visões patriarcais, provincianas e rurais. Politicamente, 68 é um ano rico em Portugal. Salazar cai da cadeira, é designado presidente vitalício e vive em São Bento certo de que continuaria a governar o país apesar de um novo Chefe de Governo ter sido nomeado. O novo governo promete liberalizar o regime. Promessa vã, que não será cumprida. A autoridade do estado está debilitada, a guerra continua. Na iminência do serviço militar obrigatório e da mobilização, a juventude contesta o regime, recusa, revolta-se, deserta. Como o futuro próximo iria demonstrar, Marcello não sucedera a Salazar: na expetativa da futura e incerta abertura do testamento, fora apenas designado administrador da herança do ditador que, rodeado de prosélitos, agonizava em São Bento. Era um tempo suspenso, o que então se vivia em Portugal, marcado pelo arcaísmo e pelos desafios do futuro e que a guerra colonial hipotecava. Os instrumentos teóricos a que eu e os companheiros 
mais próximos recorríamos eram importados de França e, através de França, da América: o anti-humanismo de Althusser, a aproximação entre o marxismo e o estruturalismo de Sebag e Poulantzas, a crítica da vida quotidiana de Lefebvre, o conceito de homem unidimensional de Marcuse. As viagens regulares a França, para ver filmes, assistir a debates e comprar livros, que depois entravam em Portugal embrulhados na roupa suja ou debaixo dos tapetes do carro, transformara-se numa necessidade vital. Passava-se por Madrid, onde as restrições à imprensa, à edição, ao cinema e ao teatro eram já incomparavelmente menos pesadas do que em Portugal. Se o dinheiro chegava, subia-se a Londres ou descia-se a Itália. Eu mantinha contactos com órgãos da extrema-esquerda europeia: a Cause du Peuple, a Lotta Continua, Il Manifesto, e com intelectuais espanhóis de correntes idênticas. Toda a Europa era um laboratório de experiências e discursos utópicos e radicais. Quando hoje viajo através das autoestradas da Europa, recordo-me sempre do que era, num dos dois Renault 4 de que fui sucessivamente o feliz proprietário, a expedição Lisboa-Madrid-Paris e volta pelas estradas inimagináveis de Portugal, Espanha e até mesmo de França, já então saturadas de pesados. Desafiando imprudentemente a polícia política, os grupos esquerdistas radicais, nos quais militava, desmultiplicavam-se em colóquios nas escolas superiores, meetings, grupos de trabalho com participação de operários, etc. Éramos jovens, ativos e irreverentes e considerávamos, inevitavelmente, que tínhamos o futuro à nossa frente. Fiz parte ativa de grupos que, por palavras e atos, romperam com a oposição unida, complacente ou colaborante com os comunistas. A extrema-esquerda dos anos 60, acima de tudo a maoísta, opunha-se ao salazarismo e, sem complexos nem reticências, recusava a ideologia e a prática dos comunistas (dos revisionistas, era a terminologia da época). Em 1967, entrei para a redação de $O$ Tempo e o Modo, revista de índole democrata-cristã - tanto quanto tal podia ser dito, implícito mais do que explícito. Um ano depois, era redator do Diário de Lisboa. Até à prisão, em 1971, ao internamento numa companhia disciplinar militar, em 1972, e ao exílio, em 1973, escrevi centenas, milhares de páginas - publicadas, censuradas, inéditas. Escrevia sobre casi todo y sobre casi nada, para citar Azorín, escritor espanhol da geração de 1898, de quem, pelos objetivos politicamente regeneradores e pela aliança entre classicismo e modernidade, desígnios similares aos da geração portuguesa de 1870, desde cedo me senti próximo. Escrevi artigos e crónicas sobre política internacional (muitos) e política nacional (menos), críticas de livros, filmes e ideias, novelas e contos. Militava clandestinamente (em rutura com o Partido Comunista desde 1966), criando contactos nacionais, ibéricos e europeus. O jornalismo e a militância política levaram-me a percorrer a Europa nos anos 60 e 70. E levaram-me à prisão, à incorporação disciplinar militar e ao exílio. Tornei-me assim, sem dar por isso, um filho do século XX, isto é, alguém que construiu, por boas e más razões, uma biografia paradigmática de uma época. Como diz uma amiga minha, a escritora espanhola Dolores Soler, referindo-se a ela própria em termos que faço meus, este enigmático século XXI em que entramos aos trambolhões, é para mim, tendo em conta a minha idade, una propina, uma gorjeta, uma dádiva dos deuses.

\section{9}

Em janeiro de 1968 participo em Dublin num seminário de organizações estudantis cujo tema é a democratização do ensino. Represento os estudantes portugueses. Viajo com identidade falsa, hospedo-me com identidade falsa e participo com o delegado espanhol (um catalão, aliás) em encontros a latere que unem os movimentos sindicalistas estudantis, isto é, 
os radicais, à margem das associações de estudantes dos países democráticos, e das organizações únicas oficiais, das ditaduras comunistas. É uma instância estudantil sindicalista que vai organizar manifestações em toda a Europa para comemorar, em 21 de fevereiro, uma jornada internacional de apoio ao povo vietnamita. Participo na coordenação em Dublin, depois em Paris. Em Portugal, uma organização ad hoc, Solidariedade Portugal-Vietname, que reúne comités Vietname que surgem nas universidades, convoca a manifestação para esse dia em frente da embaixada dos Estados Unidos. É um êxito tão grande que a polícia aparece pela primeira vez com cães polícia. Nos meses seguintes, as movimentações estudantis e as ações contra a Guerra do Vietname visam direta ou indiretamente a guerra colonial portuguesa, um tema tabu para o regime, que prende ou incorpora em regime disciplinar militar quem ousa tocar-lhe. Aí estava a especificidade portuguesa em 1968. O maio lusitano será, seis anos depois, o 25 de abril de 74.

Os jovens da geração de 68 estiveram à beira de incendiar o Ocidente? Duvido. Tratouse do primeiro grupo etário e social ocidental a ser colocado perante fenómenos impensáveis até então e que passaram a afetar diretamente os intelectuais: a transformação da ciência em força produtiva, a decadência e a redução do operariado industrial, a proletarização dos quadros e a emergência de novas formas de pobreza; enfim, e sobretudo, o desemprego massivo que espreita os universitários e a consequente depreciação da sua força de trabalho. Tudo marcos do século XXI em sociedades que pensam ainda com instrumentos do século XIX, entre os quais há que, sem apelo nem agravo, inventariar o marxismo, o sindicalismo e o igualitarismo. Perante a novidade, os jovens burgueses e pequeno-burgueses europeus e norte-americanos de há quatro décadas limitaram-se a desempenhar o papel (finalmente benéfico para o sistema) de reveladores da crise: fizeram-no com tanto mais alarido quanto a crise, que era profunda, de aguda se tornou crónica. O quotidiano do Ocidente ficou mais livre após esse sopro de libertarismo. Mas, como se tem visto, nem os pais conservadores nem os filhos esquerdistas possuíam a chave para a solução da crise. O espírito desses anos foi o espelho refletor de um conflito geracional que nada teve de inédito e que é até relativamente banal nas sociedades ocidentais modernas. Qualquer nostalgia, repito, é, a propósito, descabida: os jovens de então integram-se hoje necessariamente, inevitavelmente, e com maior ou menor ceticismo, no grupo dos gestores da crise. De acordo com um velho aforismo, é preciso ter sido incendiário aos vinte para ser bombeiro aos quarenta. Um, ex-incendiário irónico, será bombeiro tolerante e não se levará muito a sério. Outro, destituído de espírito, acabará, através das piruetas lamentáveis típicas dos convertidos, por se mostrar tão idiotamente de direita como antes o fora ingenuamente da esquerda; ou, então, transformará o radicalismo de esquerda do passado num fundamentalismo populista, com proclamações contra a globalização em nome do socialismo nacional, e por essa via antieuropeu. Deste último socialismo, da escola do comandante Chávez, temos bons exemplos em toda a Europa, e nomeadamente em Portugal, que nada têm que ver com o esquerdismo de há quatro décadas. No quadro europeu, substituem ou complementam o papel da antiga extrema-direita nacionalista. 